\title{
Responding to Child Abuse During a Pandemic
}

\author{
Victor I. Vieth, Robert J. Peters, Tyler Counsil, Rita Farrell, \\ Rachel Johnson, Stacie Leblanc, Alison Feigh, Jane Straub, and \\ Pete Singer
}

\section{Contents}

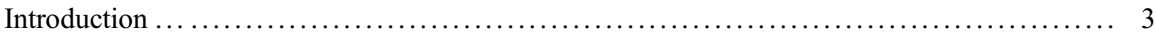

Educate Mandated Reporters About Their Role of Protecting Children During the Pandemic ... 3

This chapter is a revision of a manuscript published by Zero Abuse Project to assist child protection professionals in responding to the COVID-19 pandemic of 2020. The publication of this revised version of the chapter is reprinted with permission of Zero Abuse Project.

This chapter was initially published with an incorrect copyright holder name. It has been corrected to $($ S Springer Nature Switzerland AG.

\section{I. Vieth $(\bowtie) \cdot$ R. Johnson}

Education and Research, Zero Abuse Project, St. Paul, MN, USA

e-mail: victor@zeroabuseproject.org; rachel@zeroabuseproject.org

\section{R. J. Peters}

Zero Abuse Project, Fairmont, WV, USA

e-mail: robert.peters@zeroabuseproject.org; robert.joseph.peters@gmail.com

T. Counsil $\cdot$ J. Straub

Zero Abuse Project, St. Paul, MN, USA

e-mail: tyler@zeroabuseproject.org; jane@zeroabuseproject.org

R. Farrell

Zero Abuse Project, Fishers, MN, USA

e-mail: rita@zeroabuseproject.org

\section{S. Leblanc}

The UP Institute, CEO, New Orleans, LA, USA

e-mail: stacie@theupinstitute.com

\section{A. Feigh}

Jacob Wetterling Resource Center, Minneapolis, MN, USA

e-mail: alison@zeroabuseproject.org

P. Singer

Advanced Trauma Consulting/Zero Abuse Project, Oakdale, MN, USA

e-mail: info@advancedtraumaconsulting.com 
Educate the Public to Be on the Lookout for Signs of Abuse $\ldots \ldots \ldots \ldots \ldots \ldots \ldots \ldots \ldots \ldots \ldots$

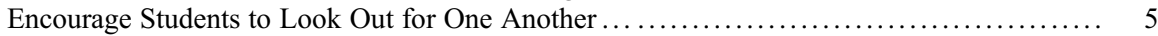

Make a List of At-Risk Children and Then Develop a Plan to Check on Them ........... 5

Develop Safety Plans and Affirmative Resources for LGBTQIA + Youth $\ldots \ldots \ldots \ldots \ldots \ldots \ldots .6$

CPS Workers Must Adjust Case and Safety Plans for Children $\ldots \ldots \ldots \ldots \ldots \ldots \ldots \ldots \ldots \ldots . \ldots$

Recognize that Children May Find Different Ways to Communicate Abuse .............. 7

Accelerate Victim Services and Court Preparation ............................... 7

Work with Youth-Serving Organizations to Modify Their Policies During the Pandemic .... 7

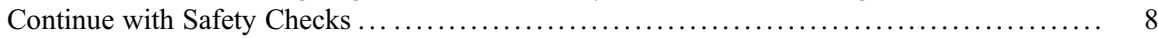

Resist Defense Attorney Initiatives that Increase the Risk of Abuse $\ldots \ldots \ldots \ldots \ldots \ldots \ldots \ldots .8$

Understand Enhanced Risks to Online Safety and Act Accordingly .................. 8

Balance the Risk of a Health Threat with the Risk of Child Abuse .................... 9

Prepare for the Unique Challenges Facing Rural Communities $\ldots \ldots \ldots \ldots \ldots \ldots \ldots \ldots \ldots \ldots .10$

Rely on Your MDT and the CAC Model ................................... 11

Consider the Mechanics of Safely Conducting Forensic Interviews and Witness Preparation

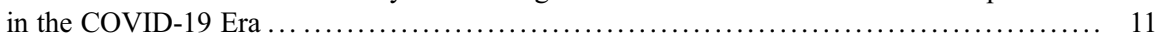

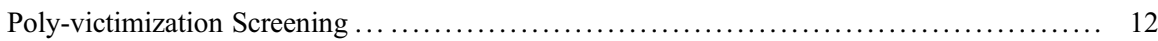

Consider the Deterrent Utility of Proactive Operations $\ldots \ldots \ldots \ldots \ldots \ldots \ldots \ldots \ldots \ldots \ldots \ldots \ldots 12$

Recognize Shifting, Safety-Focused Trends in Evidence Collection, Submission,

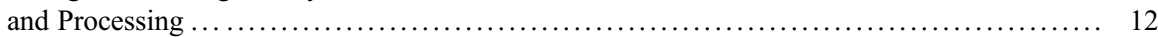

Ensure Relevant MDT Members Have Adequate Personal Protective Equipment (PPE) ..... 13

Use Appropriate Personal Protective Equipment and Follow Hygienic Best Practices ... . . . . 14

Develop a Vicarious Trauma Plan for the MDT $\ldots \ldots \ldots \ldots \ldots \ldots \ldots \ldots \ldots \ldots \ldots \ldots \ldots \ldots .14$

Recognize the Value of Spiritual Care for Child Abuse Victims and Child Protection

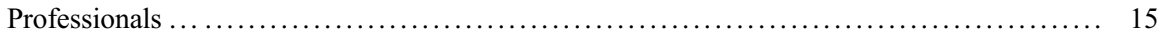

Develop Plans to Respond to Abuse Once the Pandemic Subsides ................... 16

Turn the MDTs Short-Term Plans into Long-Term Innovations $\ldots \ldots \ldots \ldots \ldots \ldots \ldots \ldots \ldots \ldots . \ldots$

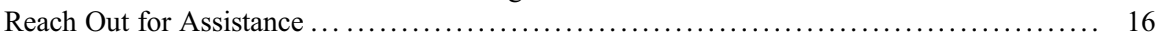

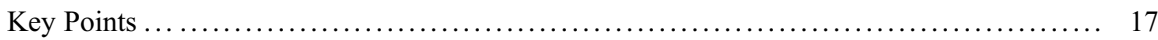

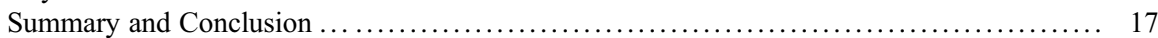

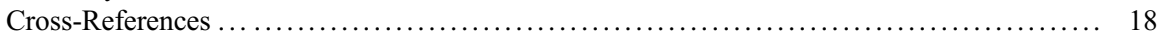

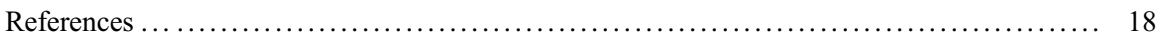

\section{Abstract}

During a pandemic, particularly a pandemic resulting in a quarantine, child abuse is likely to increase because of added stressors to a family, the isolation of children with their offenders, reduced interaction with mandated reporters, and the elimination or reduction of critical services. Using the COVID-19 pandemic as an illustration, the authors propose numerous recommendations to assist multidisciplinary teams (MDTs) responding to child abuse during a pandemic.

\section{Keywords}

Pandemic $\cdot$ COVID-19 $\cdot$ Mandated reporters $\cdot$ Multidisciplinary team

Determine that the thing can and shall be done, and then we shall find the way. Abraham Lincoln (The Abraham Lincoln Association 1953) 


\section{Introduction}

Many child protection professionals believe child abuse is likely to increase during a pandemic,. This may be particularly true during a pandemic resulting in a quarantine such as the COVID-19 pandemic of 2020 (Hirt et al. 2020). Child abuse may be more likely because most abusers are parents (Sedlak et al. 2010) or siblings (Finkelhor et al. 2009) who now have more complete access to the child victim. The added stress resulting from a pandemic, such as job loss, homeschooling obligations, and separation from loved ones are additional factors increasing the risk of abuse.

In turn, the victim may no longer have schoolteachers, faith leaders, or other mandated reporters they can access for help or who may detect a sign of abuse (Sedlak et al. 2010). Children may also have reduced access to medical and mental health providers. In responding to this concern, here are some recommendations multidisciplinary teams (MDTs) (American Prosecutor's Research Institute 2004) may wish to employ.

\section{Educate Mandated Reporters About Their Role of Protecting Children During the Pandemic}

Although children may no longer be in school, attending worship services, or involved in sports during a pandemic, they may still have contact with all of these mandated reporters through virtual activities. Accordingly, MDTs can reach out to these schools and other personnel and provide them with tips for preventing abuse. It can be as simple as distributing information to parents about managing their stress and the stress level of their children. In addition to providing prevention tips, MDTs can educate teachers and others interacting with these children to be aware of signs of abuse. Just as a child not completing his or her homework during an in-person school week may be an indicator something is wrong at home, a child failing to complete his or her homework online or who suddenly declines in school performance may likewise be struggling. It may simply be the added stress of parents and children adjusting to life during a pandemic, but, either way, additional support from a teacher or other trusted professional may aid the family.

Encourage teachers and professionals from youth serving organizations to have virtual meetings with several students at a time to discuss an activity or conduct a lesson. In this way, there is still a visual of a child's face that could detect a blackened eye or a patterned facial injury (possibly from a hand slap, belt, or cord) or injuries to the neck or ear. A live conversation may also detect yelling in a child's home or other concerning actions that may be taking place in the background. Even if yelling does not rise to a level where a report would be screened in by CPS, observing the conduct creates an opportunity for an educator or other professional to have a conversation with a parent about managing stress in a healthy way. Encourage teachers to include a conversation or at least mention the importance of children telling them or other trusted adults if they feel unsafe. 
Remind teachers that research suggests child abuse may increase when a child receives a bad report card (Bright et al. 2019). Accordingly, if they give poor grades to a child, it is essential to speak with parents in advance to try to defuse a potentially triggering event. If a parent reacts irrationally or indicates they will hit a child, the authorities should be notified. Inform the parent you will touch base with them later to see how things went with their child in the hope this will deter a parent from harsh conduct.

MDTs can provide teachers with materials they can send to parents about the danger of hitting children and provide effective alternative parenting tips to help with grades and behavior. As one example, the Play Nicely program developed by Vanderbilt University is offered in a free, online format in short segments and multiple languages that may be helpful to parents in stressful times (Vanderbilt University Medical Center 2020). The World Health Organization (WHO) has helpful guidance for parents in managing their own stress and the stress levels of their children during a pandemic. The WHO information is an additional resource that can be shared with parents (World Health Organization 2020).

MDTs can work with schools to remind teachers they remain mandated reporters even though traditional classroom time is not taking place. Providing teachers with hotline numbers and other resources to expedite reports may be helpful. MDTs should also remind medical professionals that their role in detecting abuse is even more critical during the pandemic.

\section{Educate the Public to Be on the Lookout for Signs of Abuse}

In many states, all adults are mandated reporters (Child Welfare Information Gateway 2019). Even if that is not the situation in your state, the public will play a greater role than ever before in protecting children from abuse. Educate parents and others to pay attention to the children who are in social and physical spaces with their family. If they overhear a concerning statement from a child (e.g., "mom is really drinking a lot and she forgot to the feed the baby last night" or "dad is yelling all the time and it was scary how he hit my brother today"), they need to reach out to social services or the police.

The MDT should be cognizant of increased community efforts that provide an opportunity for abuse detection. For example, educational and nonprofit organizations, faith-based associations, restaurants, and civic groups are coordinating food delivery efforts and therefore are now on the front lines of child abuse detection whether they realize it or not. MDTs should communicate with these organizations and forge creative partnerships to leverage social dynamics in their community for the benefit of local children. MDT members should consider whether key stakeholders in these efforts would be helpful ongoing additions to the MDT.

MDTs can also provider grocers and others who may be interacting with families simple tools to assist in determining if a family is at risk. For instance, MDTs may 
wish to educate grocers that patterned bruises and injuries to a child's torso, ear, or neck or on children younger than 4 months are suspicious (Tchividjian and Berkovits 2017). Free phone applications such as the Child Protector App provide helpful information on abuse indicators and accidental vs. inflicted injury (Children's Mercy Kansas City 2020). While resources such as the Child Protector App may be a helpful educational tool, the MDT should emphasize that it is not the public's role to determine the accidental or inflicted nature of an injury, but rather to report immediately whenever they have a reasonable suspicion of abuse.

\section{Encourage Students to Look Out for One Another}

Abused children often delay their disclosure for years (Alaggia 2004), with boys delaying even longer than girls (Parent and Bannon 2012). However, they may be talking to their peers about child abuse or neglect. Recognizing this, MDTs can work with schools to provide some online instruction to youth on this topic as well as an identified course of action to increase the likelihood of having a helpful response. What should a youth do, for instance, if a friend says they are being abused but makes them promise not to tell?

Many CACs regularly go into school to educate on issues of child abuse. There is no reason the same training can't continue virtually in collaboration with the schools. Furthermore, most schools are required to comply with Erin's Law (2020), which mandates age-appropriate abuse prevention education in 37 states. This law is not abrogated by the current crisis, and MDTs can partner with school personnel to continue providing this critical education. Online safety issues could also be addressed given their significance in this time.

\section{Make a List of At-Risk Children and Then Develop a Plan to Check on Them}

Perhaps utilizing the case review team, MDTs can develop a list of at-risk children known to these professionals. Once the list is developed, a plan can be implemented to make sure someone on the team or community is reaching out to each child. In some instances, it may be social services, a juvenile probation officer, a school resource officer, an educator or a faith leader, but no child should be left behind during a pandemic.

Work with courts to make sure judges know the importance of continuing at least remote contact with juveniles involved in child protection or delinquency proceedings, including juvenile drug courts, because this contact may be critical in ensuring ongoing treatment. If, for example, a child in a residential facility no longer has access to a particular service because of the pandemic, a judge may be able to order 
that accommodations be made. Ongoing judicial contact is also a critical well-being check for children isolated with their families at home.

\section{Develop Safety Plans and Affirmative Resources for LGBTQIA+ Youth}

LGBTQIA+ youth are at higher risk of abuse and neglect as a result of how people respond to their sexual orientation, gender identity and expression (SOGIE) (Baams 2018). If an MDT is working with an LGBTQIA+ child whose home environment is not affirming of the child's identities this may increase a risk of abuse or neglect during a period of quarantine. Accordingly, the MDT may want to make sure to check on the child more frequently and to keep in place any services that are affirming of the youth's identities (Human Rights Campaign 2020).

\section{CPS Workers Must Adjust Case and Safety Plans for Children}

Social workers need to modify case plans to address the medical and mental health needs of children creatively. If a child cannot be seen by a therapist during the pandemic, social services can work with the mental health provider and the families involved to establish virtual or other sessions. Mental health providers can develop checklists for youth to cope with their added anxieties, which may build resiliency in these children (Madsen 2020). Exploring local telehealth options is particularly important given the possibility of juvenile residential facility closures and the need to quickly establish ongoing community services for these youth, if courts elect to return them to their homes.

Although there is some support in the literature for telemental health (Irvine et al. 2020; Joint Task Force for the Development of Telepsychology Guidelines for Psychologists 2013; Judge et al. 2011; American Psychiatric Association 2014), MDTs also need to realize the risks of virtual sessions with children or families (Glueckauf et al. 2018). Confidentiality may be compromised if a session is being recorded. If a call brings up a sensitive subject, a child may not have the physical presence of someone who can help manage the situation, and young children are particularly reliant on this sort of co-regulation of their emotions. At the very least, there needs to be a backup plan for communication if a video connection is interrupted and cannot be re-established. There may also be insurance issues, with some providers unwilling to pay for medical or mental health services provided virtually. Training is needed to ensure competent provision of telemental health (Hilty et al. 2020).

Safety plans need to be developed for at-risk children, so they know their options if they feel their home is not safe during this pandemic. Child protection workers and attorneys should review the Department of Health and Human Services guidance for legal issues that may arise during the pandemic (Milner 2020). 


\section{Recognize that Children May Find Different Ways to Communicate Abuse}

During a pandemic, children are likely online more and may be increasingly expressing their frustrations in social media or other forums. MDTs may want to consider where the youth in their community share their fears or worries online and determine if there is a way to monitor these communications for signs of abuse. For example, some schools maintain online communication networks between students and school counselors or teachers, which is often a venue for expressing student safety concerns.

\section{Accelerate Victim Services and Court Preparation}

If there is a pending child abuse trial several months down the road, a victim services advocate may want to accelerate reaching out to a child victim if only to see how she or he is responding to the stress of the pandemic. It may be that some family members are taking advantage of the isolation to pressure a child to recant. A child may see a mother's stress of losing a job and wonder if taking back an allegation may enable an abusive father to come home and help the family. It may be a child is now being abused by the remaining parent in the home but is afraid to tell because they don't know who will take care of them if both parents are removed. A child may wonder if there will still be a trial during the pandemic or may worry about the possibility of virtual testimony because they struggle with some technology or find technology triggering because of a prior victimization in a technologyfacilitated context. A child may fear that virtual testimony will be recorded or manipulated in a way that will harm them. Simply reaching out to the child to check how they are doing may reduce not only these fears but also the risk of future abuse. Giving children as many outlets as possible to address their anxieties is critical for all victims of abuse. This is even more so during a pandemic.

\section{Work with Youth-Serving Organizations to Modify Their Policies During the Pandemic}

MDTs should assist youth serving organizations in modifying their child protection policies during the pandemic (Audage 2007). Faith communities and other child serving organizations may have child protection policies for their in-person work with children, but these need to be modified to fit this particular point in time. For instance, how are the interactions of teachers and students being monitored during this time to limit any possibility an instructor may be using this pandemic as an opportunity to groom a child for eventual abuse (Lanning 2005)? It may be as simple as requiring another adult to be copied on messages regarding homework or other activities or instructing teachers to record virtual sessions and conduct them in an appropriate location (i.e. not the teacher's bedroom). MDTs may be a resource in these modifications. 


\section{Continue with Safety Checks}

If a CPS safety plan requires periodic safety checks (Minnesota Department of Human Services 2020), this important work should not be scrapped. Instead, the MDT should explore creative options for continuing the work but minimizing the risk. This may require special equipment, establishing a plan of social distancing during the check or requiring a parent to walk around the house with a computer so the worker can see things are safe, possibly accompanied by a drive-by of the residence. If more than one agency is going into a home, perhaps work can be combined. If, for example, an officer is regularly checking on an offender living in a home, perhaps the officer can also be doing the safety check for CPS. If there are personal care attendants, nurses, or other home-based service providers still involved with a family, partnering with these agencies to reduce visits but still have safety checks in the home may be additional options.

\section{Resist Defense Attorney Initiatives that Increase the Risk of Abuse}

During the COVID-19 pandemic, defense attorneys and parent's rights attorneys advocated that traditional checks on sex offenders and families involved with child protection be relaxed or eliminated. For example, the Sex Offense Litigation and Policy Resource Center (2020, p. 2) urged the government to "suspend internet access restrictions" for sex offenders so they can access news, continue employment, and "maintain family connections." The problem with this, of course, is that sex offenders with unbridled access to the internet are at greatest risk to violate children, at a time when children are likely increasingly vulnerable to online abuse. It is telling that these proposals are often recycled arguments that predate the current pandemic and were properly rejected by courts at sentencing. It is also telling that they typically fail to mention, let alone meaningfully mitigate, the resulting risks to child safety. If the defendant's sentencing preferences endangered children pre-pandemic, the outbreak of a health threat such as COVID-19 has likely not changed that reality. When confronted with proposals such as this, government officials need to be firm in saying, "we are not going to accept a proposal that endangers children. If, though, you have suggestions for meeting your client's needs while still protecting the public, we are happy to explore healthy and safe options." There are a variety of reasonable intermediate measures that meet this standard.

\section{Understand Enhanced Risks to Online Safety and Act Accordingly}

The quantity and severity of child sexual abuse material is exponentially increasing. According to the Department of Justice, there has been a $65 \%$ increase in federal sentencing enhancements for "sadistic, masochistic, or violent images" (U.S. Department of Justice 2010, p. 22) between 2002 and 2008. Likewise, international law enforcement has noted increasingly severe acts and younger 
child victims (Bronskill 2016). Former US Attorney General Eric Holder noted that the only decrease involving child sexual abuse material "is in the age of the victims" (U.S. Department of Justice 2020). In 2004, the National Center for Missing and Exploited Children reviewed 450,000 files depicting child sexual abuse. In 2015, NCMEC reviewed 25 million files, and in 2018, 45 million files (Dance and Keller 2019). Also in 2018, NCMEC's CyberTipline received in excess of 18.4 million reports of suspected online sexual exploitation of minors.

Despite these staggering amounts, it was suggested in some areas that law enforcement processing of CyberTipline reports, as well as examination of child sexual abuse material in digital forensic labs, be halted due to concerns of COVID19. This is not acceptable. The danger of a health threat such as COVID-19 must be taken seriously and extensive precautions for officer safety must be followed, but it is unconscionable that the online exploitation of literally millions of children would be overlooked, for any length of time. While triage of cases at labs may be unavoidable, the sexual exploitation of children should certainly qualify among the most egregious crimes and be prioritized accordingly. Prosecutors, MDT members, statewide CAC coalitions, and prosecuting attorneys' associations must insist that these cases be pursued aggressively and continuously.

\section{Balance the Risk of a Health Threat with the Risk of Child Abuse}

During the COVID-19 pandemic, some MDTs were pressured to close juvenile treatment facilities or to end out of home placements for maltreated children or children who have committed sexual offenses. Although concern for contracting COVID-19 or another health threat is extremely important, this must be balanced against the risk a child will be abused or die if returned home to an abusive family. We know with certainty that ongoing child abuse poses significant long-term medical and mental health concerns (Felitti and Anda 2010), and these concerns must be fully considered. In some instances, reunification of a child with an abusive parent is prematurely urged due to suspension of visitation during the pandemic. This is an inappropriate remedy if it jeopardizes child safety, a risk which, because of the pandemic, is perhaps greater than when the child was removed. It is also an unnecessary risk when parties could accommodate remote visitation, and do so at a higher frequency than in-person visits.

In assessing the risk of a health threat, MDTs may wish to ask the following questions:

1. Has anyone in the home been diagnosed with a contagious disease or virus?

2. Has anyone in the neighborhood, school, or workplace of the family been diagnosed?

3. Has the family been following social distancing or other guidelines established by the Centers for Disease Control or other health authorities? Does a family have any incentive to be dishonest with a child protection worker or other MDT member about this issue? 
4. Is anyone in the home at high risk of contracting a contagious virus or disease because of their age or weakened immune system?

5. Is PPE available for the family and the members of the MDT interacting with the family?

6. If a home visit is required, is it possible to practice social distancing or take other precautions inside the residence?

In assessing the risk of child abuse, the MDT may wish to ask the following questions, adapted from the Structured Decision Making Manual (Sect. 1) of the Minnesota Department of Human Services:

1. Is the caregiver's current behavior violent or out of control?

2. Is the caregiver describing the child in negative or harsh terms such as calling the child worthless, or wishing the child was never born.

3. Has the caregiver caused serious physical harm in the past?

4. Does the family refuse access to a child such as denying a child protection worker the ability to speak with a child on the telephone or see a child in a screen chat?

5. Is the caregiver unwilling or unable to meet the child's basic needs for food, clothing, shelter or medical care?

6. Has the child expressed any fear of the caregiver?

\section{Prepare for the Unique Challenges Facing Rural Communities}

Many rural communities do not have a Children's Advocacy Center in their jurisdiction (Chandler 2006) and may transport child victims to a CAC an hour or more away to conduct forensic interviews (Vieth 1998). With social distancing requirements during a pandemic, this may be unwise or even unlawful in some states. MDTs should work with their state CAC coalitions and stakeholders to address this. One possibility is the mobile child advocacy center. For example, some states have refitted motorhomes into a functional CAC, including forensic interview room, MDT room, family waiting area, and recording equipment (Northern Michigan Alliance for Children 2020). Although practicing social distancing may be more challenging inside a smaller mobile CAC, the risks may be less than those of transporting a child a great distance and having them enter a traditional CAC which is larger but may have more people in the facility. The MDT could also utilize investigators or CPS workers trained in conducting forensic interviews, ensuring these are recorded and conducted in a child-friendly location and in accordance with forensic interviewing protocols.

Remote visitation can also be more difficult to accommodate in rural jurisdictions, particularly where Internet access is rare. One possibility is to have one party with poor Internet access participate in remote visitation by utilizing the visitation facility's Internet access. 


\section{Rely on Your MDT and the CAC Model}

MDT meetings should not be cancelled or sparsely attended - if anything, they are more urgent during this pandemic. While safety should be prioritized in the form of social distancing and/or virtually held meetings, all members of the MDT should recognize the inherent strength of the multidisciplinary approach, and its efficacy in crafting unique solutions to the challenges posed by our new social reality. Though trials and hearings may be delayed, there are critical functions the MDT must fulfill in the interim. When the pandemic has subsided, MDTs should be prepared to move quickly on unresolved cases. Prosecutors should urge judges to place languishing child abuse trials at the top of the docket.

\section{Consider the Mechanics of Safely Conducting Forensic Interviews and Witness Preparation in the COVID-19 Era}

Although best practice is to conduct an in-person forensic interview, the pandemic may necessitate remote interviews in at least some circumstances. MDTs should consider the legal and public health implications of conducting remote forensic interviews and how the age of children and context of abuse allegations affect this determination. A 4-year-old, for example, may not be able to participate in a remote interview, whereas a 14-year-old may be able to understand and otherwise better adapt to a remote interview.

If an interview is to be conducted remotely, precautions must be taken to prevent potentially suggestive or coercive influences, such as the unjustified presence of third parties during the child's interview. For in-person interviews, MDTs should implement social distancing and other preventative measures.

MDTs should assess the technological capabilities of the Children's Advocacy Center (CAC) to determine if there is a remote observation function where MDT members could observe an interview being conducted at the CAC without themselves being physically present in the building. Relying on the advice of medical providers on the team, forensic interview rooms, and interviewing tools such as markers or anatomical dolls, could be sanitized before and after the interview. Ideally, these and other factors should be reduced to writing in the hope of developing consistency and in order to defend the team's decision in court.

The National Children's Alliance has developed a number of resources, including webinars to assist CACs and MDTs in making these decisions and, if necessary, in conducting tele-forensic interviews (National Children's Alliance 2020). This information is being regularly updated for the field. Medical and mental health providers on the MDT or in the community may also have experience with telehealth and could provide helpful guidance. 


\section{Poly-victimization Screening}

Approximately two-thirds of maltreated children are violated in at least two ways and about one-third have experienced five or more categories of abuse - a concept known as "poly-victimization" (Turner 2010; Finkelhor 2007). This is why some forensic interviewing models employ a "poly-victimization screen" when interviewing children (Faller 2015). If it is true that child abuse will increase during the pandemic, it may be even more critical for forensic interviewers and other MDT members to screen for multiple forms of abuse when responding to a report. It is also critical for the MDT to educate mandated reporters and other members of the public on the concept of poly-victimization, thereby increasing the likelihood of detecting and reporting numerous forms of abuse.

\section{Consider the Deterrent Utility of Proactive Operations}

Many jurisdictions likely lack the investigative capacity or expertise to conduct proactive operations during this pandemic, but those which are so equipped should consider that predators are likely fully aware of the current, unique vulnerability of children. This offers an investigative opportunity to detect emboldened offenders, create compelling undercover personas, and present realistic scenarios to those seeking to target children online. Such investigations could have a deterrent effect on other offenders and send the message that pandemic or not, law enforcement will be vigilant in pursuing online exploitation. In the way that law enforcement highlights additional highway patrol monitoring for intoxicated driving on extended weekends or holidays, you may want to work with the media to highlight expanded online monitoring in the hope of deterring some offenders. Even if news coverage does not deter an offender, it serves to remind parents and others to be vigilant in monitoring online activities of their children.

\section{Recognize Shifting, Safety-Focused Trends in Evidence Collection, Submission, and Processing}

With preliminary reports indicating that COVID-19 possesses a higher basic reproduction number (R0) of 2-3 (Rettner 2020) (meaning 2-3 people are at risk for infection if exposed to one COVID-19 infected person; in comparison, influenza $R O=\sim 1.3$ ), it is vital that evidence collection specialists and laboratory staff (evidence clerks, analysts) be vigilant when working with evidence for the foreseeable future so as to mitigate the opportunity for infection, which could pose serious health risks to public servants and create unforeseen delays in evidence processing as analysts are forced to self-quarantine and/or focus on making a healthy recovery. With respect to survivability on items, a study from the New England Journal of 
Medicine found that traces of the virus may remain on cardboard up to $24 \mathrm{~h}$ (Van Doremalen et al. 2020), while non-porous items (e.g., plastic, metal) may retain the virus for up to $72 \mathrm{~h}$. In response to the potential for viral propagation in a laboratory environment, many lab agencies are reducing services (South Carolina Law Enforcement Division 2020) and limiting the processing of evidence to that of violent crimes (Crepeau and Gorner 2020). Moreover, evidence clerks are establishing strict guidelines for scheduling evidence submission appointments in advance (Virginia Department of Forensic Science 2020), restricting the number of individuals present when receiving evidence in accordance with social distancing guidelines, and setting special hours aside for intensive disinfecting services to prevent viral spread.

Medical forensic exam procedures may still be provided in a hospital setting, though some state agencies (Criminal Justice Coordinating Council 2020) and the International Association of Forensic Nurses (IAFN) (2020) are encouraging the use of non-hospital centers (e.g., sexual assault treatment centers) for collection of evidence so as to reduce the potential for infection. IAFN has also reaffirmed their stance on self-collection sexual assault kits, citing numerous concerns including but not limited to lack of access to short-term and long-term health assessments; the inability to connect to community services; failure to diagnose injuries through a specialized clinician; chain of custody and evidence admissibility challenges. Additionally, IAFN does support the use of telehealth options for assisting victims of violence and their service providers during the pandemic but suggests that forensic nurses must use technology that is HIPAA-compliant. Such options have shown merit, especially in rural communities (Wicklund 2017), and it is worth noting that the Office of Civil Rights is lessening restrictions on non-HIPAA telehealth technology given the current crisis in public health (Miliard 2020). Armed with this knowledge and knowing the variety of crimes that are perpetuated upon children (Finkelhor 2012), it is important to be aware of these recommendations and adjustments in agency policies as they may impact the timeline of resolution for your child abuse and neglect investigations.

\section{Ensure Relevant MDT Members Have Adequate Personal Protective Equipment (PPE)}

With the national shortage of PPE, many jurisdictions may have to search for local solutions. According to the National Police Foundation's COVID-19 Law Enforcement Impact Dashboard, $45.5 \%$ of surveyed law enforcement indicated a lack of sufficient PPE (National Police Foundation 2020). The MDT can coordinate with local and statewide nonprofit organizations to mitigate PPE shortages and work to protect investigators, healthcare professionals, and other MDT members. Broader public mobilization may be needed to do so (Shaver 2020). 


\section{Use Appropriate Personal Protective Equipment and Follow Hygienic Best Practices}

Using the COVID-19 pandemic as an example of need for appropriate PPE, the Centers for Disease Control and Prevention (CDC) (Occupational Safety and Health Administration 2020) concluded that COVID-19 is found in many common body fluids associated with forensic evidence, including saliva (respiratory droplets are the primary mode of infection and can deposit on item surfaces) and blood. While evidence collection specialists and laboratory analysts are not strangers to universal precautions related to evidence-related hazards (Centers for Disease Control and Prevention 2020a), it is a time to be increasingly mindful of the use of appropriate personal protective equipment (PPE). The following guidelines for first responders (e.g., crime scene investigators, sworn law enforcement) may laterally apply to forensic lab analysts, as well, given that these professionals come in direct contact with evidence that could pose a potential health risk. Note that these are recommendations in best practice for keeping those who collect and analyze evidence safe and are in no way suggestions to replace an agency's existing guidelines. Minimum PPE guidelines are as follows (Centers for Disease Control and Prevention 2020c):

- Disposable examination gloves (e.g., nitrile, latex)

- Single use/disposable coveralls

- Eye protection (e.g., goggles, face shield - preferably disposable)

- NIOSH-approved respirator (N95 or above)

$\S$ Note: The CDC states that "facemasks" (e.g., cloth masks) are an acceptable alternative until the supply chain normalizes, but the American Nurses Association challenges these claims (Washington State Nurses Association 2020); as such, work with your administration to determine a best-fit solution to respirator needs at this time in accordance with organizational policy.

In the event such PPE is not available, practice appropriate hygiene techniques (wash hands with warm water, soap after collection/processing; minimize potential for aerosolization of particulate from items; refrain from touching one's face). If disposable coveralls or a suitable substitute (e.g. gown) are not available, wash duty gear promptly after one's shift concludes and be sure to decontaminate one's patrol vehicle using CDC recommended procedures (Centers for Disease Control and Prevention 2020b).

\section{Develop a Vicarious Trauma Plan for the MDT}

If an MDT does not have a vicarious trauma plan for its members, this is a critical need to address (Vieth 2013). If you already have a plan in place, modify it to reflect the circumstances of a pandemic. In addition to the stress of addressing an increasing number of child abuse cases with diminishing resources, child protection professionals may be cut off from their families and may be worried about loved ones who 
have contracted COVID-19 or who are dying. MDT members may also be cut off from their co-workers who are often a significant source of strength and the only people in their lives who understand what they go through in their jobs.

Provide your team members with practical reminders such as stepping outside and going for a walk if they can do so safely. If they are unable to leave their house safely, give them options for in home exercises. Implement a "buddy system" where every employee takes the responsibility to check in on a co-worker regularly to see how they are doing. If your team has a mental health provider or a chaplain, enlist their aid in providing resources to the team and making themselves available for virtual conversations. Ask the board members of your CAC to write a note to the employees letting them know they are grateful for the extra efforts being made under the most difficult of circumstances. Reach out to faith communities and enlist their support in sending encouragement to MDT members. Set aside time during the week for a "coffee and conversation" virtual meeting where team members can talk about their lives outside of their work. Make sure this is done during the work day so that you do not add to your colleagues' anxiety by taking them away from home and family obligations. You may also want to share your vicarious trauma plan with schools and other youth serving organizations in the hope these professionals will be better skilled at keeping themselves healthy and, as a result, be able to serve children better.

\section{Recognize the Value of Spiritual Care for Child Abuse Victims and Child Protection Professionals}

There is a significant body of research documenting that many abused children are spiritually impacted by the trauma (Walker 2009). This is concerning, in part, because there is also a large body of research finding that spirituality is an important source of resiliency for children who have endured trauma (Bryant-Davis et al. 2012; Jungmeen 2008; Reinert et al. 2015). Indeed, a recent study in a CAC finds that spirituality may be the most importance source of resilience for many maltreated children (Jouriles et al. 2019). During a forensic interview or MDT investigation, children often raise religious or spiritual questions about their abuse (Tishelman and Fontes 2017). In order to meet the cultural competency standard of an accredited CAC, the MDT “must be willing and able to understand the clients' worldviews, adapt practices as needed, and offer assistance in a manner in which it can be utilized (National Children's Alliance 2017, p. 16)." The National Children's Alliance cultural competency standards specifically mention religion (National Children's Alliance 2017).

As a result of this large body of research, the American Psychological Association has published two treatises to assist clinicians in addressing the spiritual needs of traumatized children (Walker and Hathaway 2012; Walker et al. 2015). Some MDTs have added a trauma-informed chaplain to their case review team, and at least three CACs have hired a chaplain to address the spiritual needs of children, their families, and the MDT (Vieth and Singer 2019; Vieth et al. in press). 
If your MDT has mental health providers or trauma-informed chaplains or other faith leaders already in place to address the spiritual needs of abused children, their families, and the MDT, consider how to employ these professionals during this pandemic. If your MDT has not yet put this reform in place, make it part of your long-term plans.

\section{Develop Plans to Respond to Abuse Once the Pandemic Subsides}

After the pandemic, it is possible there will be a surge in child abuse reports as children return to schools, sports and faith activities (Wulczyn 2020). Accordingly, MDTs need to consider how they will handle a potential increase in reports. Perhaps additional personnel are needed. Perhaps there are some retired child protection professionals who can be called back to duty to help with a short term influx of cases. If additional personnel or other resources are needed, MDTs should be proactive in communicating this need to policy makers as early as possible. Ideally, MDTs will have been proactive in addressing abuse during the pandemic and thus may have flattened the curve of future reports.

Even if there is not a significant increase in new cases, there may be a backlog of old cases that have gotten worse because trials have been continued or other services interrupted. For some children, distancing and social isolation may have been beneficial because they no longer had to deal with social and other demands that caused them stress. When forced to return to a more stressful routine, some children in the child protection system may regress.

\section{Turn the MDTs Short-Term Plans into Long-Term Innovations}

As MDT members face challenges during a pandemic, they will undoubtedly engineer new ways of approaching issues and crafting solutions. These innovations to child protection should be collaboratively identified, discussed, and sustained even after the pandemic. For example, to effectively engage in abuse prevention for the foreseeable future, most MDTs must engage a broader coalition to monitor their communities and detect abuse. These relationships should be preserved and strengthened when the pandemic has subsided. Similarly, MDTs may find efficiency in some remotely delivered services, such as telehealth methods and therapy, and could identify appropriate, routine utilization of remote technology.

\section{Reach Out for Assistance}

When you encounter unique issues, from conducting a forensic interview in these unprecedented circumstances to responding to defense demands for premature release or loosening supervision restrictions, reach out to other MDT members and 
advocacy organizations for assistance. The COVID-19 pandemic clearly illustrated our collective interdependence, both in flattening the curve and in seeking justice for children.

\section{Key Points}

- Child abuse is likely to increase during a pandemic because of additional stress, the isolation of children, and a reduction of contact with mandated reporters.

- A pandemic forces MDTs to adjust traditional services to children and families.

- Although modifications may have to be made, such as wearing personal protective equipment or speaking with children virtually, critical child protection services such as safety checks, forensic interviews, investigations, and court hearings must continue.

- Mandated reporters continue to perform this role during a pandemic but may need additional tools from MDTs in order to prevent or detect maltreatment.

- Child protection policies for youth serving organizations will need to be adjusted during a pandemic to keep safe as many children as possible.

- Although a pandemic increases the risk of online victimization of children, it may also create opportunities for investigators to detect online predators.

- Poly-victimization screening is important in responding to all reports of children, but this is particularly true during a pandemic.

- Rural communities face unique challenges during a pandemic and therefore telehealth, mobile CAC vehicles, and other creative remedies will need to be considered.

- Vicarious trauma plans should be modified during a pandemic in the hope of keeping members of an MDT emotionally healthy.

- A growing body of research finds that spiritual care is an important aspect of resiliency for children, adults, and MDTs, and this aspect of caring for families and professionals should be included in our response to child maltreatment.

\section{Summary and Conclusion}

"In a crisis," said President John F. Kennedy, "be aware of the danger - but recognize the opportunity" (Goodreads 2007). Although the COVID-19 pandemic has increased the risk of child abuse and taxed the resources of our nation's CACs and MDTs, this crisis has also created opportunities. This moment in time affords the opportunity to develop new community partners and to find new ways to protect children.

It is an opportunity that, for the sake of children in need, must be seized. 


\section{Cross-References}

Child Maltreatment: Mandated Reporting

Recognizing and Responding to the Spiritual Impact of Child Abuse

The People in Your Neighborhood: Working with Sexual and Gender Minority Youth as Victims of Sexual Violence

\section{References}

Alaggia, R. (2004). Many ways of telling: Expanding conceptualization of child sexual abuse disclosure. Child Abuse \& Neglect, 28(11), 1213-1227. https://doi.org/10.1016/j. chiabu.2004.03.016.

American Prosecutor's Research Institute. (2004). Investigation and prosecution of child abuse (3rd ed.). Thousand Oaks: Sage.

American Psychiatric Association. (2014). Resource document on telepsychiatry and related technologies in clinical psychiatry. Washington, DC: American Psychiatric Association. Retrieved from http://www.psychiatry.org/learn/library\%2D\%2Darchives/resource-documents

Audage, S. (2007). Preventing child sexual abuse in youth serving organizations: Getting started on policies and procedures. Atlanta: Centers for Disease Control and Prevention, National Center for Injury Prevention and Control.

Baams, L. (2018). Disparities for LGBTQ and gender nonconforming adolescents. Pediatrics, 141(5), 1-12. https://doi.org/10.1542/peds.2017-3004.

Bright, M., Lynne, S., Masyn, K., Waldman, M., Graber, J., \& Alexander, R. (2019). Association of friday school report card release with saturday incidence rates of agency-verified physical abuse. JAMA Pediatrics, 173(2), 176-182. https://doi.org/10.1001/jamapediatrics.2018.4346.

Bronskill, J. (2016, July 4). Canadian police lack resources to keep up with online child pornography, federal memo warns. Toronto Star. Retrieved April 2, 2020, from www.thestar.com/news/ canada/2016/07/04/canadian-police-lack-resources-to-keep-up-with-online-child-pornographyfederal-memo-warns.html

Bryant-Davis, T., Ellis, M., Burk-Maynard, E., Moon, N., Counts, P., \& Anderson, G. (2012). Religiosity, spirituality, and trauma recovery in the lives of children and adolescents. Professional Psychology: Research and Practice, 43(4), 306-314. https://doi.org/10.1037/ a0029282.

Centers for Disease Control and Prevention. (2020a, March 30). Healthcare professionals: Frequently asked questions and answers. Retrieved from https://www.cdc.gov/coronavirus/ 2019-ncov/hcp/faq.html

Centers for Disease Control and Prevention. (2020b, April 1). Interim recommendations for US community facilities with suspected/confirmed Coronavirus disease 2019. Retrieved from https://www.cdc.gov/coronavirus/2019-ncov/community/organizations/cleaning-disinfection. html

Centers for Disease Control and Prevention. (2020c). What law enforcement personnel need to know about coronavirus disease 2019 (COVID-19). Retrieved from https://www.cdc.gov/coro navirus/2019-ncov/downloads/guidance-law-enforcement.pdf

Chandler, N. (2006). Children's advocacy centers: Making a difference one child at a time. Hamline Journal of Public Law and Policy, 28(1), 315-338.

Child Welfare Information Gateway. (2019). Mandatory reporters of child abuse and neglect. Washington, DC: U.S. Department of Health and Human Services, Children's Bureau. Retrieved April 1, 2020.

Children's Mercy Kansas City. (2020). Child protector app: Protecting against child abuse. Retrieved from https://www.childrensmercy.org/health-care-providers/providers/providerresources/apps-for-providers/child-protector-app/ 
Crepeau, M., \& Gorner, J. (2020, March 20). State crime lab scales back operations amid coronavirus spread, leading to shelving of drug cases. Chicago Tribune. Retrieved from https:/www.chicagotribune.com/news/criminal-justice/ct-coronavirus-state-crime-lab-impact20200320-pwcpakrajrbujhuzygoy2yy5ki-story.html

Criminal Justice Coordinating Council. (2020). Recommended COVID-19 response guidance for Medical-Forensic Services. Retrieved from https://cjcc.georgia.gov/grants/covid-19-resources/ guidance-medical-forensic-services

Dance, G., \& Keller, M. (2019, September 29). The internet is overrun with images of child sexual abuse. What went wrong? New York Times. Retrieved from https://www.nytimes.com/interac tive/2019/09/28/us/child-sex-abuse.html

Erin's Law. (2020). Erin's Law. Retrieved from http://www.erinslaw.org

Faller, K. (2015). Forty years of forensic interviewing of children suspected of sexual abuse, 1974-2014: Historical benchmarks. Social Sciences, 4(1), 34-65. https://doi.org/10.3390/ socsci4010034.

Felitti, V., \& Anda, R. (2010). The relationship of adverse childhood experiences to adult medical disease, psychiatric disorders, and sexual behavior: Implications for healthcare. In R. Lanius, E. Vermetten, \& C. Pain (Eds.), The impact of early life trauma on health and disease: The hidden epidemic 78 (pp. 77-87). New York: Cambridge University Press.

Finkelhor, D. O. (2007). Poly-victimization: A neglected component in child victimization. Child Abuse \& Neglect, 31(1), 7-26. https://doi.org/10.1016/j.chiabu.2006.06.008.

Finkelhor, D. (2012). Characteristics of crimes against juveniles. Durham: Crimes Against Children Research Center. Retrieved from http://www.unh.edu/ccrc/pdf/CV26_Revised\% 20Characteristics $\% 20$ of $\% 20$ Crimes $\% 20$ against $\% 20$ Juveniles_5-2-12.pdf

Finkelhor, D., Ormrod, M., \& Chaffin, M. (2009, December). Juveniles who commit sex offenses against minors. OJJDP Juvenile Justice Bulletin, 1-12.

Glueckauf, R., Maheu, M., Drude, K., Wells, B., Wang, Y., Gustafson, D., \& Nelson, E. (2018). Survey of psychologists' telebehavioral health practices: Technology use, ethical issues, and training needs. Professional Psychology: Research and Practice, 49(3), 205-219. https://doi. org $/ 10.1037 /$ pro0000188.

Goodreads. (2007). A quote by John F. Kennedy. Retrieved April 1, 2020, from https://www. goodreads.com/quotes/1487-the-chinese-use-two-brush-strokes-to-write-the-word

Hilty, D., Chan, S., Torous, J., Luo, J., \& Boland, R. (2020). A framework for competencies for the use of mobile technologies in psychiatry and medicine: Scoping review. JMIR mHealth and uHealth, 8(2). https://doi.org/10.2196/12229.

Hirt, S., Ball, A., \& Wedell, K. (2020, March 21). Children more at risk for abuse and neglect amid coronavirus pandemic, experts say. USA Today. Retrieved March 31, 2020, from https://www. usatoday.com/story/news/investigations/2020/03/21/coronavirus-pandemic-could-becomechild-abuse-pandemic-experts-warn/2892923001/

Human Rights Campaign. (2020). All children - All families: LGBTQ considerations for safety plans. Retrieved from https://www.hrc.org/resources/all-children-all-families-lgbtq-consider ations-for-safety-plans

International Association of Forensic Nurses. (2020, March 25). COVID-19: A video message to our members. Retrieved from https://www.forensicnurses.org/news/493334/-COVID-19-a-mes sage-to-our-members.htm

Irvine, A., Drew, P., Bower, P., Brooks, H., Gellatly, J., Armitage, C., .. Bee, P. (2020). Are there interactional differences between telephone and face-to-face psychological therapy? A systematic review of comparative studies. Journal of Affective Disorders, 265(15), 120-131. https:// doi.org/10.1016/j.jad.2020.01.057.

Joint Task Force for the Development of Telepsychology Guidelines for Psychologists. (2013). Guidelines for the practice of telepsychology. American Psychologist, 68(9), 791-800. https:// doi.org/10.1037/a0035001. 
Jouriles, E., Rancher, C., Mahoney, A., Kurth, C., Cook, K., \& Mcdonald, R. (2019). Divine spiritual struggles and psychological adjustment among adolescents who have been sexually abused. Psychology of Violence. https://doi.org/10.1037/vio0000274.

Judge, A., Abeles, N., Davis, S., Adam-Terem, R., \& Younggren, J. (2011). Report from the society for the advancement of psychotherapy task force on telepsychotherapy. Retrieved from http:// www.societyforpsychotherapy.org/report-task-force-telepsychotherapy

Jungmeen, K. (2008). The protective effects of religiosity on maladjustment among maltreated and nonmaltreated children. Child Abuse \& Neglect, 32(7), 711-720. https://doi.org/10.1016/j. chiabu.2007.09.011.

Lanning, K. (2005). Acquaintance child molesters: A behavioral analysis. In S. Cooper, R. Estes, A. Giardino, N. Kellog, \& V. Vieth (Eds.), Medical, legal, and social science aspects of child sexual exploitation. Florissant: STM learning Inc.

Madsen, M., \& Resilience for Children and Families (2020). Available online at https://www.apsac. org/covid-19. Last accessed 2 Apr 2020.

Miliard, M. (2020, March 18). OCR will ease restrictions on telehealth tech during COVID-19. Healthcare IT News. Retrieved from https://www.healthcareitnews.com/news/ocr-will-easerestrictions-telehealth-tech-during-covid-19

Milner, J. (2020, March 27). An open letter to child welfare legal and judicial leaders [open letter]. Retrieved from https://cdn.ymaws.com/www.nysda.org/resource/resmgr/covid-19_pdfs/jerry_ milner 3272020 covid.pdf

Minnesota Department of Human Services. (2020). The structured decision making system for child protective services: Policies and procedures manual. Madison: Children's Research Center.

National Children's Alliance. (2017). Standards for accredited members. Washington, DC: National Children's Alliance. Retrieved from http://www.nationalchildrensalliance.org/wp-con tent/uploads/2015/06/NCA-Standards-for-Accredited-Members-2017.pdf

National Children's Alliance. (2020). COVID-19 resources for CACs, partners, and caregivers. NCA Learning Center. Retrieved from https://learn.nationalchildrensalliance.org/covid

National Police Foundation. (2020). Coronavirus (COVID-19): Resources for Law Enforcement. Retrieved from https://www.policefoundation.org/covid-19/

Northern Michigan Alliance for Children. (2020). Northern Michigan mobile child advocacy center. Retrieved from https://www.mikids.org/gomobile

Occupational Safety and Health Administration. (2020). Healthcare wide hazards. Washington, DC: U.S. Department of Labor. Retrieved from https://www.osha.gov/SLTC/etools/hospital/ hazards/univprec/univ.html.

Parent, S., \& Bannon, J. (2012). Sexual abuse in sport: What about boys? Child Abuse and Neglect, 34(2), 354-359. https://doi.org/10.1016/j.childyouth.2011.11.004.

Reinert, K., Campbell, J., Bandeen-Roche, K., Lee, J., \& Szanton, S. (2015). The role of religious involvement in the relationship between early trauma and health outcomes among adult survivors. Journal of Child \& Adolescent Trauma, 9(3), 231-241. https://doi.org/10.1007/ s40653-015-0067-7.

Rettner, R. (2020, March 25). How does the new coronavirus compare with the flu? Retrieved April 2, 2020, from https://www.livescience.com/new-coronavirus-compare-with-flu.html

Sedlak, A., Mettenburg, J., Basena, M., Petta, I., McPherson, K., Greene, A., \& Li, S. (2010). Fourth national incidence study of child abuse and neglect (NIS-4): Report to congress. Washington, DC: U.S. Department of Health and Human Services, Administration for Children and Families.

Sex Offense Litigation and Policy Resource Center. (2020). COVID-19: Strategies for reducing transmission. St. Paul: Sex Offense Litigation and Policy Resource Center. Retrieved from https://mitchellhamline.edu/sex-offense-litigation-policy/wp-content/uploads/sites/61/2020/03/ SOLPRC-COVID-19-Guidance-March-28-1.pdf

Shaver, J. (2020, March 27). United way of Marion, Taylor Co., WV, participates in masks for WV. Fairmont News. Retrieved from https://www.wvnews.com/fairmontnews/news/united- 
way-of-marion-taylor-co-wv-participates-in-masks-4-wv/article_3d7d5406-b2c1-561f-82b8762e3902cbe3.html

South Carolina Law Enforcement Division. (2020). Evidence submission procedures COVID-19 contingency plan. Columbia: South Carolina Law Enforcement Division. Retrieved from http:// www.sled.sc.gov/documents/COVID/2020-02\%20COVID-19\%20Contingency\%20Plan\%20$\% 20$ Forensic\%20Services.pdf

Tchividjian, B., \& Berkovits, S. (2017). The child safeguarding policy guide for churches and ministries. Greensboro: New Growth Press.

The Abraham Lincoln Association. (1953). Collected works. (R. Basler, M. Pratt, \& L. Dunlap, Eds.) New Brunswick: Rutgers University Press. Retrieved April 1, 2020, from https://quod.lib. umich.edu/l/lincoln/lincoln1/1:498? rgn=div1; view=fulltext

Tishelman, A., \& Fontes, L. (2017). Religion in child sexual abuse forensic interviews. Child Abuse \& Neglect, 63, 120-130. https://doi.org/10.1016/j.chiabu.2016.11.025.

Turner, H. A. (2010). Poly-victimization in a national sample of children and youth. American Journal of Preventive Medicine, 38(3), 323-330. https://doi.org/10.1016/j.amepre.2009.11.012.

U.S. Department of Justice. (2010). The national strategy for child exploitation prevention and interdiction: A report to Congress. Washington, DC: U.S. Department of Justice. Retrieved from https://www.justice.gov/psc/docs/natstrategyreport.pdf

U.S. Department of Justice. (2020). Child pornography. Retrieved April 2, 2020, from www.justice. gov/criminal-ceos/child-pornography

Van Doremalen, N., Bushmaker, T., Morris, D., Holbrook, M., Gamble, A., Williamson, B., Tamin, A., Harcourt, J., Thornburg, N., Gerber, S., Loyd-Smith, J., de Wit, E., \& Munster, V. (2020). Aerosol and surface stability of HCoV-19 (SARS-CoV-2) compared to SARS-CoV-1. New England Journal of Medicine, 1-3. https://doi.org/10.1101/ 2020.03.09.200332.

Vanderbilt University Medical Center. (2020). Play Nicely: The healthy discipline program. Jr. Children's Hospital at Vanderbilt: Monroe Carell.

Vieth, V. (1998). In my neighbor's house: A proposal to address child abuse in rural America. Hamline Law Review, 22, 143.

Vieth, V. (2013). The View from the trenches: Recommendations for improving South Carolina's response to child sexual abuse based on insights from frontline child protection professionals. Winona: Gundersen National Child Protection Training Center. Retrieved April 1, 2020, from https://cdn2.zeroabuseproject.org/wp-content/uploads/2019/02/d996bcbb-ncptc-silent-tearsfinal-report.pdf

Vieth, V., \& Singer, P. (2019). Wounded souls: The need for child protection professionals and faith leaders to recognize and respond to the spiritual impact of child abuse. Mitchell Hamline Law Review, 45(4), 1213-1234. Retrieved from https://open.mitchellhamline.edu/mhlr/vol45/iss4/6

Vieth, V., Everson, M., Vaughan-Eden, V., Tiapula, S., Galloway-Williams, S., \& Nettles, C. (in press). Keeping faith: The potential role of a chaplain to address the spiritual needs of maltreated children and advise child abuse multi-disciplinary teams. Liberty Law Review, 14, 349.

Virginia Department of Forensic Science. (2020). COVID-19 updates. Retrieved from https://www. dfs.virginia.gov/covid-19-updates/

Walker, D. F. (2009). Changes in personal religion/spirituality during and after childhood abuse: A review and synthesis. Psychological Trauma Theory Research Practice and Policy, 1(2), 130-145. https://doi.org/10.1037/a0016.

Walker, D., \& Hathaway, W. (Eds.). (2012). Spiritual interventions in child and adolescent psychotherapy. Washington, DC: American Psychological Association.

Walker, D., Courtois, C., \& Aten, J. (Eds.). (2015). Spiritually-oriented psychotherapy for trauma. Washington, DC: American Psychological Association.

Washington State Nurses Association. (2020, March 24). Cloth masks don't protect nurses. Retrieved from https://www.wsna.org/news/2020/cloth-masks-dont-protect-nurses 
Wicklund, E. (2017, August 21). Telemedicine may prove valuable in rural sexual assault cases. $m$ Health Intelligence. Retrieved from https://mhealthintelligence.com/news/telemedicine-mayprove-valuable-in-rural-sexual-assault-cases

World Health Organization. (2020). Mental health and psychosocial considerations during the COVID-19 outbreak. Geneva: World Health Organization. Retrieved from https://www.who.int/ docs/default-source/coronaviruse/mental-health-considerations.pdf

Wulczyn, F. (2020). Looking ahead: The Nation's Child Welfare Systems after Coronavirus. The Chronicle of Social Change. Retrieved from https://chronicleofsocialchange.org/childwelfare-2/looking-ahead-the-nations-child-welfare-systems-after-coronavirus/41738 